\title{
COMPARISON OF VALIDITY OF FNACAND ZIEHL-NEELSEN STAINS IN DIAGNOSING CERVICAL TUBERCULOUS LYMPHADENITIS
}

\author{
Aisha Qaiser, Muhammad Sohail Babar Niazi*, Zaheer Ul Hassan*, Shahid Farroq Khattak*, Shahid Iqbal**, Sunarays Akhtar*** \\ Fauji Foundation Hospital, Peshawar Pakistan, *Combined Military Hospital Peshawar/National University of Medical Sciences (NUMS) Pakistan, ${ }^{* *}$ Combined \\ Military Hospital Gujranwala/National University of Medical Sciences (NUMS) Pakistan, ***PAF Hospital, Lahore Pakistan
}

\section{ABSTRACT}

Objective: To compare the validity of FNAC \& ZN staining in diagnosing tuberculous lymphadenitis taking mycobacterial culture as gold standard.

Study Design: Cross sectional study.

Place and Duration of Study: Pathology department, Fauji Foundation Hospital Peshawar, from Oct 2019 to Sep 2020.

Methodology: This study includes 100 patients with enlarged cervical lymph nodes who presented as outdoor patients. After routine baseline \& radiological investigations, FNAC \& ZN staining was carried out, followed by mycobacterial culture.

Results: FNAC of tuberculous patients was positive in $56(56 \%)$ patients while $24(24 \%)$ patients revealed posi-tive mycobacterial culture. Inpatients with positive culture, $77(77 \%)$ were FNAC positive and $23(23 \%)$ were negative on cytology.

Conclusion: Fine needle aspiration is more sensitive \& specific test than Ziehl-Neelsen staining.

Keywords: Acid Fast Bacilli, Fine needle aspiration cytology, Hematoxylin \& eosin stain, Ziehl-Neelsen staining.

How to Cite This Article: Qaiser A, Niazi MSB, Hassan ZU, Khattak SF, Iqbal S, Akhtar S. Comparison of Validity of FNAC and Ziehl-Neelsen Stains in Diagnosing Cervical Tuberculous Lymphadenitis. Pak Armed Forces Med J 2021; 71 (Suppl-3): S484-486. Doi: https://doi.org/10.51253/pafmj.v1i1.7928

This is an Open Access article distributed under the terms of the Creative Commons Attribution License (https://creativecommons.org/licenses/by-nc/4.0/), which permits unrestricted use, distribution, and reproduction in any medium, provided the original work is properly cited.

\section{INTRODUCTION}

Tuberculosis (TB), a contagious disease is one of the leading cause of morbidity as well as mortality in Pakistan. It is a bacterial infection caused by mycobacterium tuberculosis that spreads commonly from cough and sneeze of infected persons. ${ }^{1}$ Males are affected more than females especially with advancing age. ${ }^{2}$

Cervical tuberculous lymphadenopathy is one of the most commonpresentation of extra pulmonary tuberculosis. ${ }^{3}$ Since cervical lymph nodes enlargement is mostly superficial therefore it is easy to perform fine needle aspiration cytology for obtaining diagnostic material that is further aided by ZN staining., ${ }^{4,5}$ FNAC is rapid, cost-effective \& reliable method of staining especially in those setups where culture takes long time to obtain results. ${ }^{6,7}$ The objective of study is to compare the validity of FNAC \& $\mathrm{ZN}$ staining in diagnosing tuberculous lymphadenopathy taking mycobacterial culture as gold standard. The rationale of this study is that FNAC is more helpful in evaluation \& definite in diagnosis as compared to $\mathrm{ZN}$ staining. It helps in better decision making for better treatment options.

\section{METHODOLOGY}

This cross sectional study was performed in Pathology department of Fauji Foundation Hospital,

Correspondence: Dr Muhammad Sohail Babar Niazi, ENT Department, Combined Military Hospital Peshawar Pakistan
Peshawar, from October 2019 to September 2020. Using non-probability purposive sampling technique a total of 100 cases of clinically suspected patients of tuberculous lymphadenitis were selected.

Inclusion Criteria: All patients with positive family history \& clinical signs \& symptoms (cough with or without hemoptysis, fever, weight loss, dyspnea) of tuberculosis.

Exclusion Criteria:The patients on anti-TB treatment.

The patients of both genders (male \& female) of age range (15-60 years) were selected. The history, sign \& symptoms \& demographic data was collected from all patients. After ultrasound scan of neck nodes, FNAC was done. At least two smears were developed for every case. One smear was prepared for H\&E staining and the second smear for ZN staining. For mycobacterial culture, the residuary aspirate was used.

For epithelioid granulomas, necrosis \& presence of AFB (H\&E \&ZN stained) smears were put to examination.

To perform mycobacterial culture, the specimens were subjected to Lowenstein-Jensen (LJ) Medium. It is a glycerated egg based medium used as selective medium for the growth of mycobacterium tuberculosis. After inoculation, it takes maximum of four weeks for the appearance of colonies (brown, granular "buff" colonies). 
The criteria for confirmed diagnosis of tuberculous lymphadenitis included necrotic epithelioid cell granuloma with positive AFB on $\mathrm{ZN}$ stain and positive mycobacterial culture. Data was tabulated \& analysis was done by using SPSS version 20 .

\section{RESULTS}

A total of 100 cases of patients with clinical suspicion of tuberculous lymphadenopathy reporting to hospital. Age of the patient ranged from (15-65 years) with mean age is 42 years. The most commonly affected individuals were of 4 th decade of life. Out of $30 \%$ of the patients were less than 30 years while $8 \%$ were less than 20 years.There were 60 males \& 40 females with male female ratio is (3:2). Most common associated symptoms were fever \& cough with $10 \%$ having past history \& $13 \%$ had history of TB contact.

FNAC of tuberculous patients was positive in $56(56 \%)$ patients while $24(24 \%)$ patients revealed positive mycobacterial culture. Inpatients with positive culture, $77(77 \%)$ were FNAC positive and $23(23 \%)$ were negative oncytology. In case of FNAC the sensitivity, specificity, positive predictive value and negative predictive value of FNAC were $77 \%, 43 \%, 30 \%$ and $83 \%$ respectively whereas for Zeil Nelson staining for AFB sensitivity, specificity, positive predictive value and negative predictive value were $15 \%, 97 \%$, $74.2 \%$ and $77.5 \%$ respectively.

Table-I: Diagnostic efficacy of FNAC against bacterial culture.

\begin{tabular}{|c|c|c|c|c|c|}
\hline & \multicolumn{2}{|c|}{ Growth on Culture } & & \multirow{2}{*}{$\begin{array}{c}p \text { - } \\
\text { value }\end{array}$} \\
\hline & & Yes (\%) & No $(\%)$ & & \\
\hline \multirow{3}{*}{ 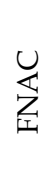 } & $\begin{array}{l}\text { Epitheliod } \\
\text { cells seen }\end{array}$ & 18 (76.9) & $39(66.4)$ & 57 (57\%) & \multirow{3}{*}{$<0.001$} \\
\hline & $\begin{array}{l}\text { Epitheliod } \\
\text { cells not seen }\end{array}$ & $5(23)$ & $38(49.33)$ & $43(43 \%)$ & \\
\hline & Total & $23(100)$ & $77(100)$ & $100(100 \%)$ & \\
\hline
\end{tabular}

Table-II: Result of ZN staining for Acid fast bacillus against bacterial culture.

\begin{tabular}{|c|c|c|c|c|c|}
\hline & & \multicolumn{2}{|c|}{ Growth on Culture } & & \multirow{2}{*}{$\begin{array}{c}p \text { - } \\
\text { value }\end{array}$} \\
\hline & & Yes (\%) & No (\%) & & \\
\hline \multirow{3}{*}{$\begin{array}{l}\text { Zeil } \\
\text { Nelson } \\
\text { stain } \\
\text { (Acid fast } \\
\text { Bacillus) }\end{array}$} & + ve & $3(14.9)$ & $2(2)$ & $5(5.4 \%)$ & \multirow{3}{*}{$<0.001$} \\
\hline & -ve & $\begin{array}{c}20 \\
(85.1) \\
\end{array}$ & $\begin{array}{c}75 \\
(97.5) \\
\end{array}$ & $\begin{array}{c}95 \\
(94.6 \%) \\
\end{array}$ & \\
\hline & Total & $23(100)$ & $\begin{array}{c}77 \\
(100) \\
\end{array}$ & $\begin{array}{c}100 \\
(100 \%) \\
\end{array}$ & \\
\hline
\end{tabular}

\section{DISCUSSION}

Both FNAC \& ZN stains play an important role in preoperative assessment of patients in cervical tuberculous lymphadenitis. Aim of this study is to evaluate diagnostic accuracy of FNAC \& ZN stains \& to study the comparison ofits utility, dependability \& precision of diagnosis in suspected cases of tuberculous lymphadenitis. The study reveals that the patients (100 in number) were referred to Pathology Department of Fauji Foundation Hospital for lymph nodes FNAC. Since most of the patients fall within age range of (3050) years, the disease prevalence is associated with advancing age. The gender distribution is associated with poor nutritional status, decreased immunity \& personal habits (smoking etc).

The study indicates mostly cervical lymph node involvement followed by supraclavicular \& axillary lymph nodes. Presence of clusters of epithelioid cells (granulomas) \& caseous necrosis is the hallmark of cytomorphological features of tuberculosis on FNAC. FNAC has a documented sensitivity in endemic areas of $97-100 \%$ \& specificity ranges from $88-100 \%$ while in non-endemic the sensitivity is found low. In this study the sensitivity, specificity, positive predictive value $\&$ negative predictive value of FNAC are $76.9 \%, 43.1 \%$, $30.4 \%$ and $83.2 \%$ respectively. The negative culture \& positive cytomorphological features (H\&E) indicate non tuberculous granulomatous inflammation inadequate amount of viable mycobacteria to allow growth on culture medium.

The results shown in the study were similar to the research conducted by Prasad et al and Saboorian et al.8,9 Roskell et al and Getachew et al were also convinced of the efficacy of FNAC in the diagnosis of tuberculosis lymphadenitis. ${ }^{10,11} \mathrm{Hashmi}$ et al conducted a similar study about the role of FNAC in lymphadenopathy with similar results to our study. ${ }^{12,13}$ FNAC has also been shown to be a quite accurate and useful tool in diagnosing other head and neck tumors as well. ${ }^{14-8}$

\section{CONCLUSION}

The accurate technique to diagnose cervical tuberculous lymphadenitis is FNAC having high sensitivity \& specificity than ZN stain. Culture should only be used in suspicious cases of mycobacterial infection and gives a reliable technique for the identification of various species of mycobacterium. and disease.

\section{Conflict of Interest: None.}

\section{Authors' Contribution}

AQ: Conceived the main idea, developed study design, MSBN: Bibliography, ZUH: Manuscipt drafting, SFK: Helped in data interpratation, SI: Research supervisor, SA: Developed study tool, literature survey

\section{REFERENCES}

1. Nidhi P, Sapna T,Shalini M, Kumud G. FNAC in tuberculous lymphadenitis: experience from a tertiary level referral centre. Ind J Tuberc 2011; 58(3): 102-107. 
2. Mittal P, Handa U, Mohan H, Gupta V. Diagn Comparative evaluation of fine needle aspiration cytology, culture, and PCR in diagnosis of tuberculous lymphadenitis. Cytopathol 2011; 39(11): 822-826.

3. Handa U, Mundi I, Mohan S. Nodal tuberculosis revisited: a review. J Infect Dev Ctries 2012; 6(1): 6-12.

4. Mitra SK, Misra RK, Rai P. Cytomorphological patterns of tubercular lymphadenitis and its comparison with Ziehl-Neelsen staining and culture in eastern up. (Gorakhpur region): Cytolo-gical study of 400 cases. J Cytol 2017; 34(3): 139-143.

5. Verma K, Kapila K. Aspiration cytology for diagnosis of tuberculosis-perspectives in India. Ind J Pediat 2002; 69(Suppl-1): S39-43.

6. Sharma SK, Mohan A. Extrapulmonary tuberculosis. Indian J Med Res 2004; 120(4): 316-353.

7. Bilal JA, Elshibly EM, Sudan J. Etiology and clinical pattern of cervical lymphadenopathy in Sudanese children 2012; 12(1): 97103.

8. Prasad R, Garg SK, Mukerji PK, Agarwal PK. Role of fine needle aspiration cytology in the diagnosis of lymphadenopathy. Ind J Chest Dis Allied Sci 1993; 35(1): 27-29.

9. Saboorian MH, Ashfaq R. The use of fine needle aspiration biopsy in the evaluation of lymphadenopathy. Semin Diagn Pathol 2011; 8(1): 110-123.

10. Roskell DE, Buley ID. Fine needle aspiration cytology in cancer diagnosis. Br Med J 2004; 329(2): 244-245.
11. Getachew A, Tesfahunegn Z. Is fine needle aspiration cytology a useful tool for the diagnosis of tuberculous lymphadenitis?. East Afr Med J 1999; 76(2): 260-263.

12. Hashmi AA, Naz S,Ahmed O, Yaqeen SR,Irfan M,Kamal A, Faridi N. Utility of fine needle aspiration cytology in the evaluation of lymphadenopathy 2020; 12(1): e11990.

13. Naz S, Hashmi AA, Khurshid A, Faridi N, Edhi MM, Kamal A, et al. Diagnostic role of fine needle aspiration cytology (FNAC) in the evaluation of salivary gland swelling: an institutional experience. BMC Res Notes 2015; 8(1): 101-105.

14. Asim M, Mudassir G, Hashmi AA.Diagnostic accuracy of fine needle aspiration biopsy in pediatric small round cell tumors. BMC Res Notes 2018; 11(2): 573-575.

15. Naz S, Hashmi AA, Khurshid A, Faridi N, Edhi MM. Diagnostic accuracy of Bethesda system for reporting thyroid cytopathology: an institutional perspective. Int Arch Med 2014; 7(1): 46-52.

16. Naveed H, Abid M, Hashmi AA, Edhi MM, Sheikh AK, Mudassir G, et al. Diagnostic accuracy of touch imprint cytology for head and neck malignancies: a useful intra-operative tool in resource limited countries. BMC Clin Pathol 2017; 17(2): 25-28.

17. Steel BL, Schwartz MR, Ibrahim R. Fine needle aspiration biopsy in diagnosis of lymphadenopathy in 1,103 patients. Acta Cytologica 1995; 39: 76-81.

18. Rapkiewicz Amy, Bich Thuy Le, Aylin Simsir, Joan Cangiarella, Pascale Levine. Cancer Cytopathol 2007; 111: 242-51. 